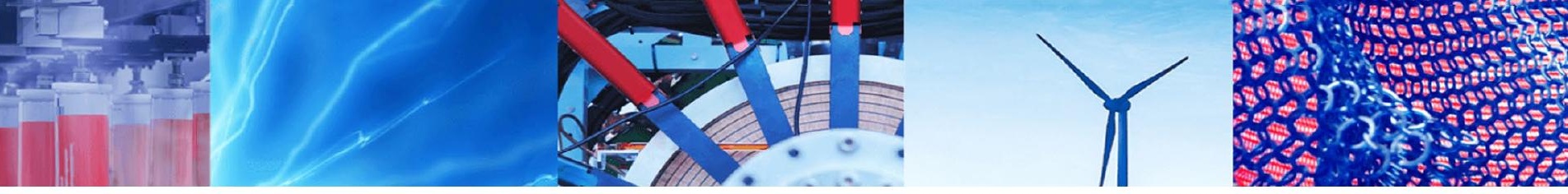

Review Paper

\title{
Actuator selection and sizing for valves
}

\author{
Karan Sotoodeh ${ }^{1}$ \\ (c) Springer Nature Switzerland AG 2019
}

\begin{abstract}
An actuator is a machine or component installed on the top of an industrial valve for automatically moving and controlling the valve. The performance of a valve is largely dependent on its actuator. Three factors are important for engineers to consider when selecting an actuator: frequency of operation, ease of access, and critical functions. Valve actuators should perform several functions including moving the valve closure member to an appropriate position, holding the valve closure member in the desired position, providing enough force or torque for seating the closure member and meeting the required shut down leakage class, providing fully open or fully close or failure mode as is, or providing a certain amount of closure member rotation with the right speed. In general, actuator can be hydraulic, pneumatic or electrical. This paper discusses the mechanism plus advantages and disadvantages of these three types of actuators. Affected parameters for actuator selection include the availability of a power source, torque and size of the valve, failure mode, speed of operation, frequency and ease of operation, control accessories, hazardous area, and cost. This paper presents a case study of breakaway torque (break to open) calculation and actuator sizing for a full-bore ball valve in pressure Class 300 equal to 50 barg nominal pressure and $22 \mathrm{Cr}$ duplex body material. The valve is fail close with an emergency shut down function, and a pneumatic actuator was selected for the valve. Fail close means that the valve will close in case of losing the power used as a source of actuator operation. Other four torque values were provided from the valve supplier. The calculated breakaway valve force and torque were used as a basis for actuator air cylinder sizing assuming air pressure of $7 \mathrm{barg}$ and system efficiency of $90 \%$. Force and torque for closing the valve were used to calculate the spring movement as well as spring piston length through Hook's law.
\end{abstract}

Keywords Valve automation · Actuator · Quarter turn or linear movement · Electrical · Pneumatic · Hydraulic

\section{Introduction to valve actuation}

An actuator is a machine or component installed on the top of an industrial valve for automatically moving and controlling the valve. Actuators are used in the plants more than before to provide better and more precise control on the valve operation [1]. According to statistics published by European Industrial Forecasting in 2015, approximately $75 \%$ of the valves in the oil and gas sector are automated by actuators [2].

A valve actuator can be defined simply as a black box with a receiving signal or power supply through air or oil pressure that produces torque for valve movement as an output. The quality of a valve depends on many parameters such as metallurgy, mechanical strength, machining, etc., whereas the performance of the valve is largely dependent on the actuator [1]. When selecting an actuator, engineers have three primary factors to consider: frequency of operation, ease of access, and critical functions [2]. Valves with high numbers of operation are proper choices and possibilities for actuation. Valves in remote or hazardous areas where the presence of an operator is dangerous should be also considered for automation. Other reasons for valve actuation include ensuring safe,

$\triangle$ Karan Sotoodeh, karan_sqi@yahoo.com; karan.sotoodeh@bhge.com | ${ }^{1}$ Manifold Engineering, Baker Hughes, a GE Company, Høvik, Norway.

SN Applied Sciences (2019) 1:1207| https://doi.org/10.1007/s42452-019-1248-z

Received: 1 June 2019 / Accepted: 10 September 2019 / Published online: 12 September 2019 
reliable, or fast operation [2]; excessive valve torque; and emergency operation of a valve to the open or closed position [1]. Valve actuators should perform several functions including moving the valve closure member to the suitable position such as open or closed, holding the valve closure member in the desired position, providing enough force or torque necessary to seat the closure member and meet the required shut down leakage class, providing fully open or fully closed or failure mode as is, and providing a certain amount of closure member rotation with the correct speed [3].

\section{Actuator types}

In general, there are three types of actuators: hydraulic, pneumatic, and electrical $[4,5]$.

\subsection{Hydraulic actuators}

A hydraulic actuator is a cylinder that works with hydraulic power and converts it to mechanical work. Hydraulic actuators can be quarter turn (Fig. 1), which are used for ball valves, or linear, which are selected for linear valves such as globe valves [6]. High pressure oil in a pressure range between 160 and 200 barg, for example, enters the cylinder of the actuator, pushes the spring back, and transfers the linear movement to quarter turn $\left(90^{\circ}\right)$ movement through scotch and yoke.

Figure 2 shows a linear spring return actuator, in which the piston is pushed back in the piston side through the force of hydraulic fluid entering the cylinder side [7]. There is no scotch and yoke in a linear actuator, so the movement of the actuator piston rod that connects to the valve stem is linear. It is possible to have double acting hydraulic actuators as per Fig. 3 utilizing pressurized oil on both sides for opening and closing the valve. There is no spring in

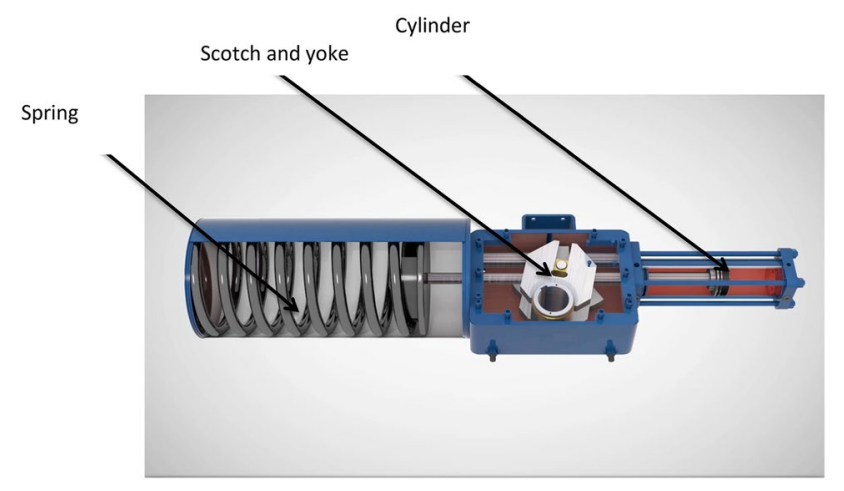

Fig. 1 Quarter turn hydraulic actuator

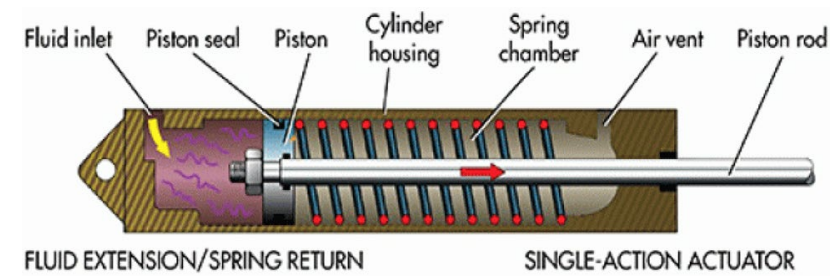

Fig. 2 Linear hydraulic actuator

double acting actuators to move the valve to either open or closed positions [8].

Advantages of hydraulic actuators are listed below [2]:

- Hydraulic actuators are smaller than pneumatic actuators since oil pressure is higher than air, so less oil is required for moving the spring compared to air. However, the hydraulic actuator is thicker than pneumatic due to higher oil pressure. For example, the air pressure in pneumatic actuators is 5.5-9 barg, which is much lower than oil pressure. It should be noted that barg is used for indicating the gauge pressure.

- Hydraulic actuators are good choice for large size and high-pressure class valves having high force or torque requirements for operation at high speed.

- Hydraulic actuators are more precise than pneumatic actuators since hydraulic oil is not compressible.

- Hydraulic actuators have a higher degree of corrosion protection compared to air or gas, which is important in corrosive environments such as offshore.

- Hydraulic actuators can reach the safe predefined position (open/closed) after losing the source of oil power through spring force.

Disadvantages of hydraulic actuators are listed below [2]:

- The high pressure of hydraulic fluid is complex to manage, requiring many safety and environmental precautions.

- The control system of hydraulic actuators is larger and more expensive compared to pneumatic.

\subsection{Penumatic actuators}

Pneumatic actuators are simple mechanical devices that convert the air pressure to mechanical work. The working principal is same as hydraulic actuators but they work with air instead of oil. This type of actuator could be either linear or quarter turn (Fig. 4). For example, the air pressure that enters the cylinder part of the actuator is between 5.5 and 9 barg.

Advantages of pneumatic actuators are listed below [2]: 


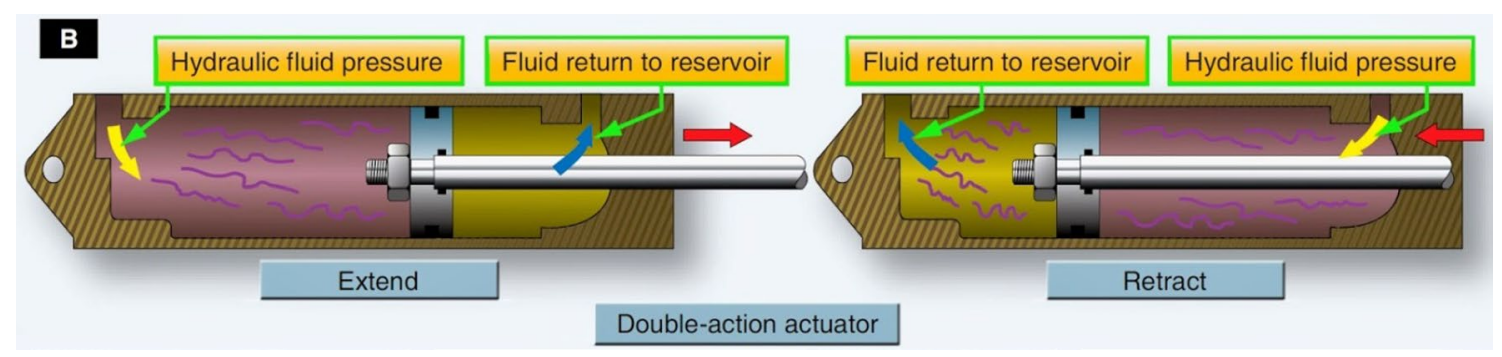

Fig. 3 Double acting hydraulic actuator

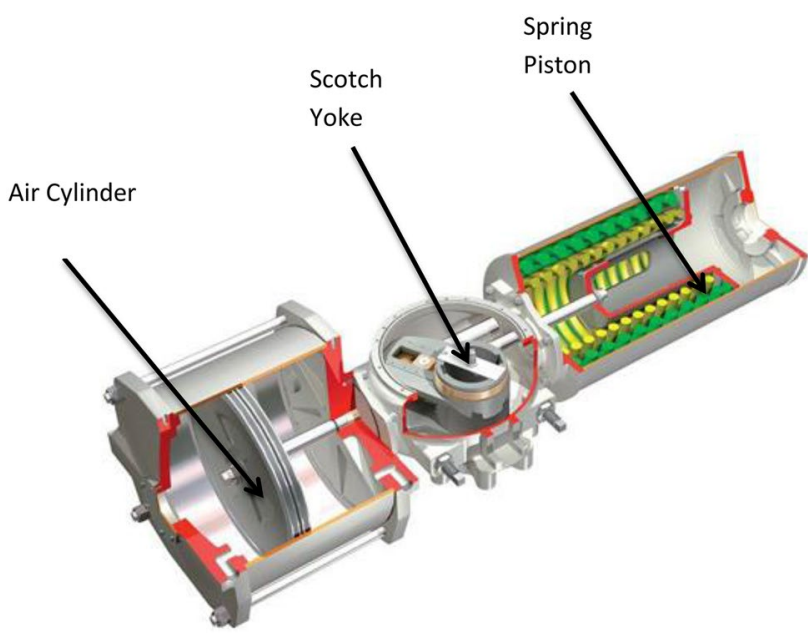

Fig. 4 Quarter turn pneumatic actuator

- Pneumatic actuators run on compressed air, which is a readily available safe fluid and environmentally friendly unlike oil [2], so they could be the best option in hazardous areas [1].

- Control systems of pneumatic actuators are relatively inexpensive and more compact compared to hydraulic actuators.

- This actuator provides high speed operation and returning to a safe position in case the air power source is lost, unlike electrical actuators.

Disadvantages of pneumatic actuators are listed below [2]:

- Pneumatic actuators are more costly compared to electrical actuators.

- Air is a compressible fluid, which can jeopardize the accuracy of the pneumatic actuators.

\subsection{Electrical actuators}

Electrical actuators (Fig. 5) use electrical power for actuation of the valves [2]. In fact, electric actuators are geared

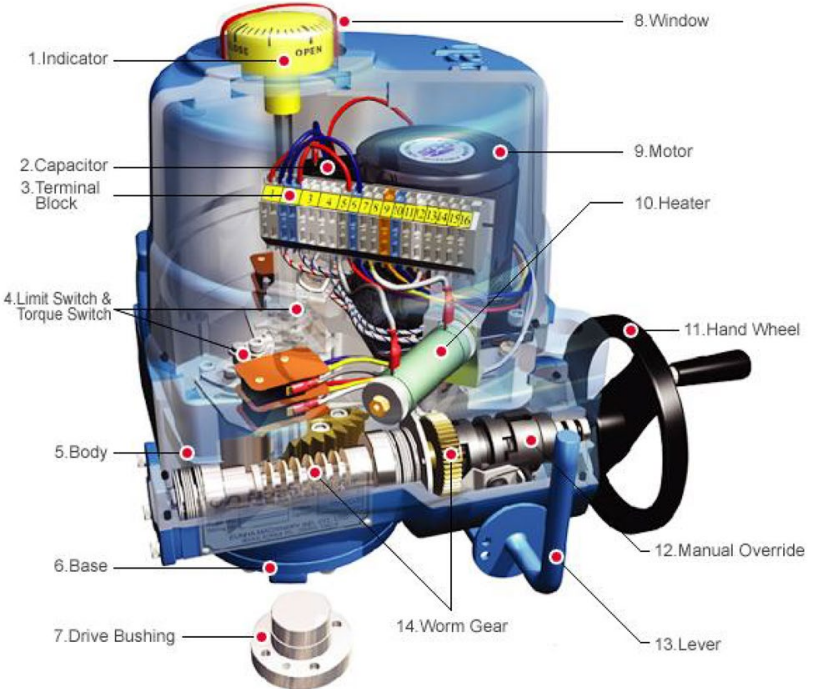

Fig. 5 Electrical actuators

motors with different electrical accessories such as limit switches and circuit boards [1]. The motor works on with $12,24,115$, or 220 AC or DC voltage.

Advantages of electrical actuators are listed below [2]:

- Electrical power is relatively inexpensive.

- Electrical actuators provide good accuracy on valve movement and functioning and it is possible to monitor the opening percentage of the valve.

- All control components are integrated into the actuator, unlike pneumatic and hydraulic actuators.

- Electrical actuators are cheaper, more compact, and lighter than pneumatic and hydraulic actuators.

Disadvantages of electrical actuators are listed below [2]:

- Electrical actuators cannot maintain fail safe positions unless they are combined with hydraulic power (electrical-hydraulic actuators). 
- Electrical actuators contain more complex and sensitive components compared to pneumatic and hydraulic actuators.

- Electrical actuators are not as economical as pneumatic or hydraulic actuators above certain sizes.

- Electrical actuators require more certifications in hazard areas with explosive fluids such as ATEX. ATEX stands for atmospheres explosive and it is a European Union Directive covers equipment and protective systems for use in potentially explosive atmosphere.

\section{Parameters that affect actuator selection}

The following parameters can affect the type of actuator that should be selected for a valve $[2,3]$ :

1. Availability of power source: A hydraulic actuator cannot be used on a plant if no source of high-pressure oil is available.

2. Torque and size of the valve: Large size and high pressure class valves (such as a 30" Class 1500 ball valve) require high torque for operation. Selection of a very large pneumatic actuator for such a large valve is not economical. A hydraulic actuator is recommended in this case.

3. Failure mode: Pneumatic and hydraulic actuators stand in open or closed positions during a power loss, unlike electrical actuators. These types of valves are spring return, which means that upon power or signal failure, the spring returns the valve to a predefined safe position [1]. Therefore, for example, electrical actuators are not suitable for emergency shut down valves that should be fully closed if power is lost.

4. Speed of operation: Electrical actuators operate valves more slowly than pneumatic and hydraulic actuators, so an electrical actuator may not be an appropriate choice if an operations speed of $1 \mathrm{in} . / \mathrm{s}$ or faster is expected from the valve.

5. Frequency and ease of operation: It is common to use electrical actuators for certain large size valves that are operated frequently instead of manual operation, for ease of operation. For example, a 20" class 300 manual ball valve with frequent operation is proposed to be equipped with an electrical actuator just for ease of operation.

6. Control accessories: Control accessories in electrical actuators are integrated into the actuator, unlike pneumatic and hydraulic actuators. In fact, electrical actuators do not require any space for control accessories, which is an advantage. Hydraulic actuators have larger control panels compared to pneumatic actuators.
7. Hazardous areas: The use of electrical actuators in a hazardous environment may be limited in some cases. Different hazard zones and classes are defined based on present of flammable gases or vapours that may put restriction in usage of the electrical actuators.

8. Cost: Electrical actuators are the cheapest type of actuators, hydraulic actuators are the most expensive and pneumatic lie between.

\section{Case study of torque calculations on a valve}

This case study examines a $10^{\prime \prime}$ full bore ball valve in $22 \mathrm{Cr}$ duplex material and Class 300 working at $30^{\circ} \mathrm{C}$ based on API 6D standard [9]. The valve is fail close with an emergency shout down function. The first step is to select the most suitable actuator. Electrical actuators do not have fast opening and closing capabilities, so either a pneumatic or hydraulic actuator should be selected for this valve. The valve is not large and the pressure class is low, so a pneumatic actuator is the best choice for this valve. The type of pneumatic actuator is scotch and yoke due to quarter turn functionality of the ball valve. The second step is to calculate the maximum torque required to open the valve at maximum pressure differential (the breakaway torque) $[4,5]$. A practical way to calculate the amount of torque is to multiply the force by the lever arm. The force produced on the valve stem by pneumatic air is perpendicular to the lever arm (stem). Therefore, torque is calculated using Eq. 1:

$\tau=\mathrm{F} \times \mathrm{r}$

where $\tau=$ magnitude of breakaway torque to open the valve $(\mathrm{Nm}) ; \mathrm{F}=$ force applied on the bare stem valve $(\mathrm{N})$; $r=$ lever arm (In this case, the distance between where the force is applied on the top of the bare stem to the centre of the valve closure member, with the rotation equal to stem plus stem extension length) (m)

The force applied on the bare stem valve should overcome unbalanced forces resulting from the pressure drop; impart sufficient force to the seat to prevent leakage and overcoming the packing friction [10]. Force on a bare stem valve is calculated using Eq. 2:

$F_{\text {total }}=F_{\text {pressure drop }}+F_{\text {seat }}+F_{\text {packing }}$

Note Friction forces of bearing has been considered as a part of packing friction forces.

Although there are seat forces due to fluid pressure as well as spring loads behind the seats, the seat force has been assumed to zero in this case to simplify the calculations. Figure 6 shows a ball valve and its components including seat, ball, stem, and stem sealing (packing). 


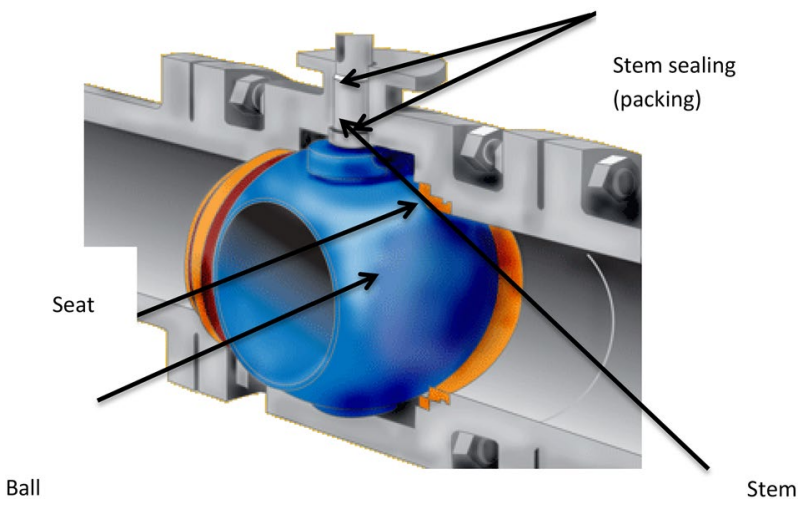

Fig. 6 Ball valves and parts

Pressure drop across the valve creates unbalanced force, which is calculated using Eq. 3:

$F_{\text {pressuredrop }}(\mathrm{N})=$ seat area $\left(\mathrm{m}^{2}\right) \times$ pressure drop $\left(\mathrm{N} / \mathrm{m}^{2}\right)$

The seat is placed around the ball of the ball valve, as shown in Fig. 7.

Therefore, the area of the seat is calculated using Eq. 4:

Seat area $=\frac{\pi}{4}\left(\right.$ seat external bore ${ }^{2}-$ ball bore $\left.{ }^{2}\right)$

The ball valve is $10^{\prime \prime}$ full bore and class 300 , so the minimum bore of this valve is $252 \mathrm{~mm}$ [9]. Assuming $3 \mathrm{~mm}$ extra radios on each side gives $6 \mathrm{~mm}$ extra diameter, the seat external bore is $252+6=258 \mathrm{~mm}$. Placing the values in Eq. 4:

$$
\begin{aligned}
\text { Seat area } & =\frac{\pi}{4}\left(258^{2}-252^{2}\right)=\frac{\pi}{4} \times 3060 \\
& =2403.25 \mathrm{~mm}^{2}=0.0024032 \mathrm{~m}^{2}
\end{aligned}
$$

The maximum pressure drop across a valve is equal to the valve maximum pressure class. This value for a class 300 Class valve in $22 \mathrm{Cr}$ duplex body at $30^{\circ} \mathrm{C}$ is

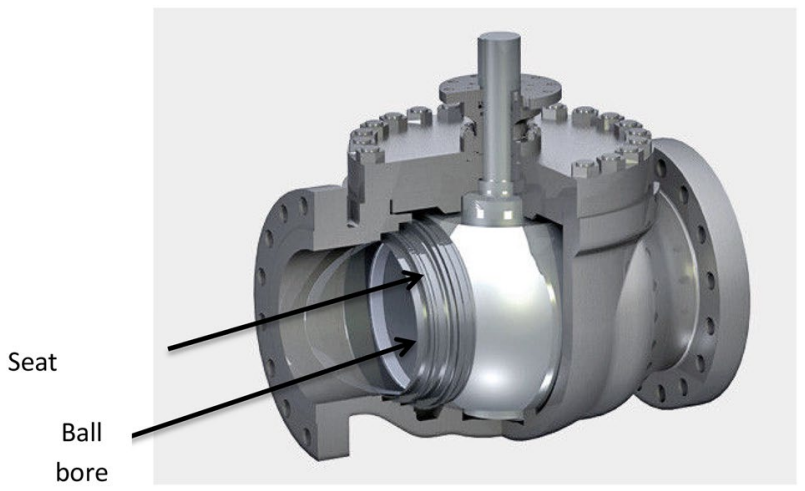

Fig. 7 Seat around the ball hole (bore) in a ball valve
51.7 barg [11]. It should be noted that 1 bar $=100,000$ $\left(\mathrm{N} / \mathrm{m}^{2}\right)$. Therefore, the pressure drop across the valve is $5,170,000\left(\mathrm{~N} / \mathrm{m}^{2}\right)$. Now it is possible to calculate the force of the pressure drop using Eq. 3:

$$
\begin{aligned}
F_{\text {pressure drop }} & =0.0024032 \times 51.7 \times 100,000 \\
& =12,424.544 \mathrm{~N}
\end{aligned}
$$

Assuming the stem diameter of $1 / 2$ " is equal to $12.5 \mathrm{~mm}$ and double reinforced PTFE packing [10], it is possible to obtain the packing friction (force) from Table 1:

Therefore, $F_{\text {packing }}=428$ and now it is possible to calculate the total force on the bare stem valve using Eq. 2:

$F_{\text {total }}=12,424.544+428=12,852.544 \mathrm{~N}$

The stem length including the stem extension is $217 \mathrm{~mm}$, and the torque can be calculated using Eq. 1:

$\tau=12,852.544 \times 0.217$

$=2789 \mathrm{~N} \mathrm{~m}$ (breakaway torque $=$ break to open torque)

There are six torque values associated with valves including ball valves [12]:

1. Break to open (BTO): This torque is measured when the valve is closed and the ball opens against just one seat under pressure. This torque, also called breakaway torque, was calculated earlier.

2. Running torque (RT): The torque of the valve when the ball opens at approximately $35^{\circ}-45^{\circ}$.

3. End to open (ETO): The torque of the valve when the ball opens at $80^{\circ}$ position closed to fully open the valve.

4. Break to close (BTC): When the valve is in fully open position, the torque required to break the open position of the valve to close the valve.

\begin{tabular}{|c|c|c|c|c|}
\hline \multirow[t]{2}{*}{$\begin{array}{l}\text { Stem diameter } \\
(\mathrm{mm})\end{array}$} & \multirow{2}{*}{$\begin{array}{l}\text { ASME } \\
\text { pressure } \\
\text { class }\end{array}$} & \multicolumn{3}{|c|}{$\begin{array}{l}\text { Packing type and related friction } \\
\text { forces }\end{array}$} \\
\hline & & Single PTFE & Double PTFE & $\begin{array}{l}\text { Rein- } \\
\text { forced } \\
\text { PTFE }\end{array}$ \\
\hline \multirow[t]{5}{*}{12.5} & 150 & 170 & 250 & 284 \\
\hline & 300 & & & 428 \\
\hline & 600 & & & 563 \\
\hline & 900 & & & 720 \\
\hline & 1500 & & & 855 \\
\hline
\end{tabular}

5. End to close (ETC): The torque required to fully close the valve when the valve is about to close.

Table 1 Typical packing friction forces [10] 
6. BTO with double block: This torque is measured when the valve is close and the ball opens against both seats under pressure.

Figure 8 shows the position of the ball in different torque conditions.

The other torque values for the ball valve had been measured by the ball valve supplier:

$E T C=1390 \mathrm{~N} \mathrm{~m}, \quad R T=1230 \mathrm{~N} \mathrm{~m}$,

$E T O=1390 \mathrm{Nm}, \quad B T C=2786 \mathrm{Nm}$

\section{Case study of actuator sizing}

As shown in Fig. 4, a scotch and yoke actuator was selected for the valve in this case study. Figure 9 shows the operation of this actuator as the air force moves the piston and the rod:

The next step is to size the air cylinder and piston spring as well as select the appropriate spring for generating the correct torque values. The air pressure entering the air cylinder is 7 barg. The safety factor for the emergency shut

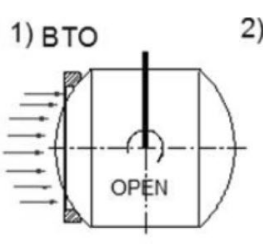

2) RUN
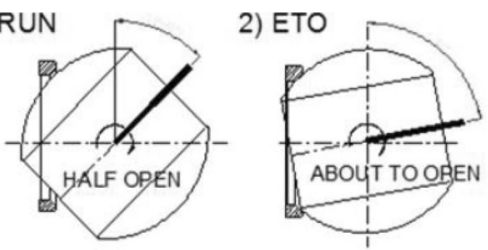

4) BTC

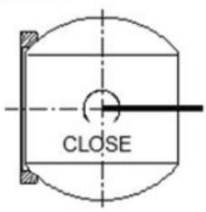

5) ETC

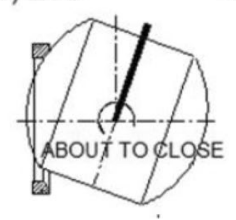

6) BTO WITH DOUBLE BLOCK

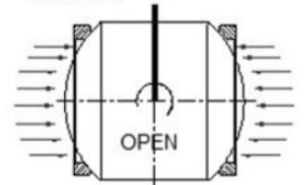

Fig. 8 Position of the ball in different torque conditions down valve in this example is 2 . This means that the actuator should produce torque values at least double the valve torque values. The efficiency of the system is assumed as $90 \%$, which means that there is $10 \%$ air pressure loss in the system. The required thrust force to open the valve is $12,852.544 \mathrm{~N}$, calculated from Sect. 4 . Now it is possible to calculate the diameter of the actuator using Eq. 5 :

$\mathrm{F}=\mathrm{P} \times \mathrm{A} \times \mu$

where $F=$ force produced on the valve stem $(N)$ for opening the valve; $\mathrm{P}=$ air pressure $\left(\mathrm{N} / \mathrm{m}^{2}\right) ; \mathrm{A}=$ area of the applied force $\left(\mathrm{m}^{2}\right) ; \mu=$ Efficiency $=90 \%$

The area of the applied force relationship to the diameter of the cylinder is calculated using Eq. 6:

$\mathrm{A}=\frac{\pi \mathrm{D}^{2}}{4}$

where $A=$ area of the applied force $\left(m^{2}\right) ; D=$ diameter of the cylinder $\left(\mathrm{m}^{2}\right) ; \mathrm{P}=$ air pressure $=7 \mathrm{Bar}=700,000 \mathrm{~N} / \mathrm{m}^{2}$; and $\mathrm{F}=12,852.544 \mathrm{~N}$ (using Eq. 5) $\rightarrow 12,852.544=700,000$ $\times A \times 0.9 \rightarrow A=(12,852.544 / 700,000 \times 0.9)=0.020 \mathrm{~m}^{2}$;

Using Eq. (6)

$$
\begin{aligned}
0.020 & =\frac{\pi D^{2}}{4} \rightarrow D^{2}=(4 \times 0.020) / 3.1415 \\
& =0.026 \mathrm{~m}^{2} \rightarrow D=0.16 \mathrm{~m}=160 \mathrm{~mm}
\end{aligned}
$$

The next step is to calculate the amount of rod movement inside the cylinder. The safety factor for sizing the actuator is 2 , which means that the torque of the actuator should be a minimum of double the torque of the valve, theoretically speaking (Eq. 7):

$$
\begin{aligned}
\text { Safety factor } & =\frac{\text { actuator torque }(\text { BTO) }}{\text { valve torque }(\text { BTO) }} \\
2 & =\frac{\text { actuator torque }(\text { BTO) }}{2789} \\
& \rightarrow \text { actuator torque }(\text { BTO) } \\
& =2 \times 2789=5578 \mathrm{~N} \mathrm{~m}
\end{aligned}
$$

Fig. 9 Scotch-yoke actuator converting linear to rotary motion
Cylinder diameter
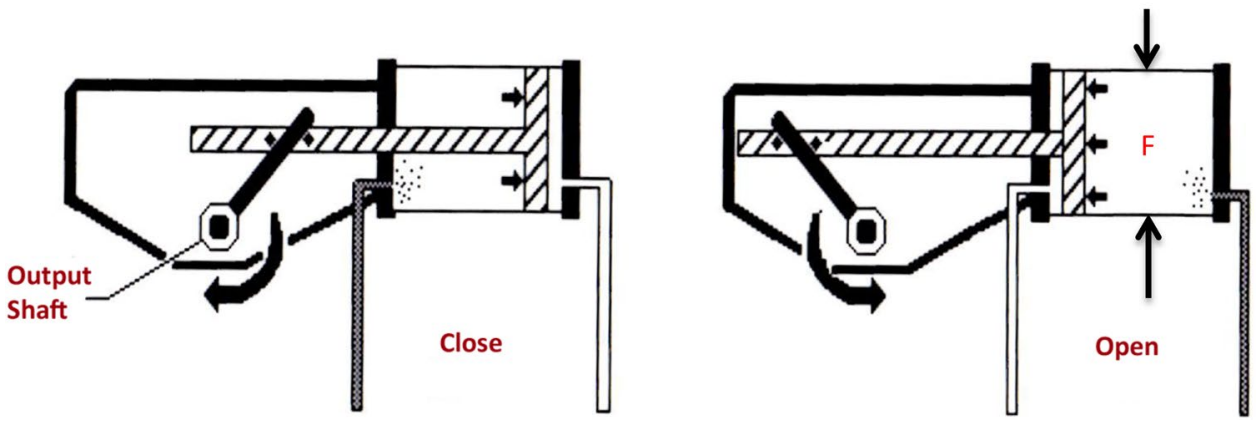
Refer to Eq. 1, $\tau=F \times r$, which can be used for the BTO torque created by the actuator. $r$ is the movement distance of the rod due to air pressure.

Therefore:

$$
\begin{aligned}
5578 & =12,852.544 \times r \\
& \rightarrow r=5578 / 12,852.544 \\
& =0.434 \mathrm{~m}=434 \mathrm{~mm}
\end{aligned}
$$

Assuming $16 \mathrm{~mm}$ for thickness of the rod end, the length of the air cylinder is $450 \mathrm{~mm}$.

The next step for actuator sizing is to calculate the spring piston size as well as the correct spring selection for closing the valve. Spring starts closing the valve through BTC torque calculated using Eq. 8.

$$
\begin{aligned}
\text { Safety factor } & =\frac{\text { actuator torque }(B T C)}{\text { valve torque }(B T C)} \\
& =\frac{\text { spring torque }(B T C)}{\text { valve torque }(B T C)} \\
& \rightarrow 2=\frac{\text { actuator torque }(B T C)}{2786} \\
& \rightarrow \text { actuator torque }(B T C) \\
& =\text { spring torque }=2 \times 2786=5572 \mathrm{~N} \mathrm{~m}
\end{aligned}
$$

Equation 9 shows the relationship between the torque and force for closing the valve.

Torque for closing the valve (BTC)

$=$ force for closing a fully open valve $\times$ stem length

$\rightarrow 2786=\mathrm{F} \times 0.217 \rightarrow$ force for closing the valve

$=2786 / 0.217=12,839 \mathrm{~N}$

Assuming the spring constant $(\mathrm{K})$ is equal to $25,000 \mathrm{~N} / \mathrm{M}$, it is possible to calculate the displacement of the spring using Hooke's law (Eq. 10):

$\mathrm{F}=\mathrm{KX}$ Hooke's law

where F: force $(\mathrm{N})$; K: spring constant $(\mathrm{N} / \mathrm{M})$; $\mathrm{X}$ : spring extension $(\mathrm{m})$

$X=F / K=12,839 / 25,000=0.513 \mathrm{~m}=513 \mathrm{~mm}$.

Assuming the preliminary length of the spring (compressed spring) to be $100 \mathrm{~mm}$, then the spring piston is $513+100=613 \mathrm{~mm}$.

The piston diameter is assumed to be equal to the cylinder diameter, which is $160 \mathrm{~mm}$.

\section{Conclusion}

This article examined a case study of breakaway torque (Break to Open) calculation and actuator sizing for a bare stem full bore ball valve in pressure Class 300 and $22 \mathrm{Cr}$ duplex body material. The valve is fail close with an emergency shut down function, and a pneumatic actuator was selected for the valve. The force for opening the valve should overcome the packing friction as well as unbalanced force due to the pressure differential. Four other torque values were provided from the valve supplier. The safety factor for actuator sizing is assumed to be equal to 2 . The calculated breakaway valve force and torque were used as a basis for actuator air cylinder sizing assuming an air pressure of 7 barg and system efficiency of $90 \%$. Additionally, force and torque for closing the valve were used to calculate the spring movement as well as spring piston length through Hook's law. The diameter of the spring housing was assumed to be equal to the diameter of the air cylinder.

\section{Compliance with ethical standards}

Conflict of interest The authors declare that they have no conflict of interest.

\section{References}

1. Indelac Controls Inc. (2014) How to select an actuator. Comprehensive Guide. http://www.indelac.com/pdfs/How-toSelect-an-Actuator-Comprehensive-Guide.pdf. Accessed 20 July 2018

2. Flowserve (2018) Valve actuation: the when, how, and why of actuator selection. https://www.flowserve.com/sites/defau It/files/2018-05/(FLS-VA-EWP-00005-EN-EX-US-0518-Actua tion_Type_Advantages_LR1.pdf. Accessed 20 July 2018

3. Metalphote of Cincinnati (2018) How to select a valve actuator: types of valve actuators, appropriate sizing, safety criteria, and more. https://www.mpofcinci.com/blog/how-to-select-avalve-actuator/\#Function. Accessed 20 July 2018

4. American Petroleum Institute (API) (2012) Standard for actuator sizing and mounting kits for pipeline valves. API 6DX, 1st edn. API, Washington

5. International Organization for Standardization (ISO) (2011) Petroleum and natural gas industries-mechanical integrity and sizing of actuators and mounting kits for pipeline valves. ISO 12490, 1st edn. Switzerland

6. Schlumberger (2018) LEDEEN hydraulic actuators and controls. https://www.products.slb.com/valves/brands/ledeen/ ledeen-hydraulic-actuators. Accessed 20 July 2018

7. Gonzalez C (2015) What is the difference between pneumatic, hydraulic and electrical actuators? Machine design. https:// www.machinedesign.com/linear-motion/what-s-difference -between-pneumatic-hydraulic-and-electrical-actuators. Accessed 20 July 2018 
8. Pishock D (2016) Choosing between a double acting and spring return actuator. https://valveman.com/blog/doubl e-acting-vs-spring-return-actuators/. Accessed 20 July 2018

9. American Petroleum Institute (API) (2014) Specification for pipeline and piping valves. API 6D, 24th edn. API, Washington, DC

10. Nesbitt $B$ (2007) Handbook of valves and actuators: valves manual international, 1st edn. Elsevier, Oxford

11. American Society of Mechanical Engineers (ASME) (2004) Valves-flanged, threaded, and welding end. ASME B16.34, ASME, New York, NY
12. Gokilakrishnan G, Divya S, Rajesh R, Selvakumar V (2014) Operating torque in ball valves-a review. Int J Technol Res Eng 2(4):311-315

Publisher's Note Springer Nature remains neutral with regard to jurisdictional claims in published maps and institutional affiliations. 